\title{
Developing a new method for modifying over-allocated multi-mode resource constraint schedules in the presence of preemptive resources
}

\author{
Aidin Delgoshaei*, Ajwad Al-Mudhafar and Mohd Khairol Annuar Ariffin
}

Department of Mechanical and Manufacturing Engineering, University Putra Malaysia, 43400 UPM, Kuala Lumpur, Malaysia

\begin{tabular}{l}
\hline C H R O N I C L E \\
\hline Article history: \\
Received February 25, 2016 \\
Received in revised format: \\
March 28, 2016 \\
Accepted May 17, 2016 \\
Available online \\
May 192016 \\
\hline Keywords: \\
Project management \\
Planning and control \\
Resource management
\end{tabular}

\section{Introduction}

Manufacturing projects are very important investing projects which can build the economy of a country. They may include establishing a new factory, setting up a new manufacturing line and constructing official buildings. Manufacturing projects can directly or indirectly influence on the economy of a country and therefore noticeable quotas of the annual budget of any country are planned based on manufacturing projects. Nowadays in production rivalry world, manufacturing systems need to plan and control the manufacturing projects in details to avoid extreme financial harms impose to their companies as improper scheduling of the manufacturing projects. For example consider a case where

* Corresponding author.

E-mail address: delgoshaei.aidin@gmail.com (A. Delgoshaei)

(C) 2016 Growing Science Ltd. All rights reserved.

doi: $10.5267 /$ j.dsl.2016.5.002 
a company decides to establish a new production line which is considered as a manufacturing project. Any delays beyond the initial completion day will cause losing thousands of dollars of profit per day.

Similar to other projects, manufacturing projects need resources to be completed. Unfortunately, limits in providing resources, makes them to be risky in terms of renewable and non-renewable resources. Hence scheduling the manufacturing projects in terms of constraint resources and investigating their impacts on project completion day and profit of the project is a vital.

Resource-constrained Project scheduling problem (RCPSP) was first developed with the aim of reducing makespan of the project (Kelley, 1963). Traditionally, classic RCPSP models were developed for minimizing makespan (Talbot, 1982). But, during last 2 decades, scientists have developed more RCPSP problems considering varied objectives. Mainly, authors developed RCPSP while 4 main optimization objectives are taken into consideration:

\section{Makespan $\left(C_{\max }\right)$ minimization}

Minimizing makespan where an attempt is accomplished to minimize the total elapsed time among time horizon of a project. In this manner, a time dependent cost structure for minimizing completion time by using extra resources which cause faster execution of activities was developed by Achuthan \& Hardjawidjaja (2001). Effects of the serial and parallel scheduling schemes while using multi- and single-project approaches were analysed later (Lova and Tormos, 2001). It was found that using parallel scheduling schemes and multi-project approach provide a basis for managers to minimize mean project delay or multi-project duration increasing. Alcaraz \& Maroto (2001) developed a GA for solving single mode RSPCP. They showed that GA could efficiently solve RCPSPs in an acceptable computation time. In the same year, GA was also employed by Hartmann (2001) for minimizing $C_{\text {max }}$ in MRCPSP and then using a local search extension motor for the proposed GA, results were more improved. Kim et al. (2005) proposed a hybrid of GA with fuzzy logic controller (FLC-HGA) to solve the resourceconstrained multiple project scheduling problem (RC-MPSP). The proposed approach worked based on using genetic operators with fuzzy logic controller (FLC) through initializing the revised serial method with precedence and resources constraints. Using fuzzy concepts in minimizing $C_{\max }$ was carried out by Ke \& Liu (2010) in a fuzzy-based GA. Delgoshaei et al. (2015) proposed a backward method for minimizing makespan in the resource constrained project scheduling problem. For this purpose they used a hybrid greedy and genetic algorithm. The novelty of their research is using remained resources through the calendar of the project to minimize the completion time of the project.

\section{Optimizing robustness of solutions}

For this purpose normally a trade-off between quality-robustness and solution-robustness in RCPSP will be determined while safety times in project scheduling were taken into consideration (Van de Vonder et al., 2005). Afterward, Van de Vonder et al. (2006) focused on resource constraint impacts in determining trade-off values between quality-robustness and solution-robustness in RCPSP. Lee \& Lei (2001) presented 2 versions of resource-constraint multi project scheduling problem where in first version, the activity durations are considered fixed but in second one, a project duration function is used to decrease the amount of resource allocating. Afterward, an attempt has been done for minimizing $C_{\text {max }}$, as well as maximizing solution robustness by increasing float time maximization (Abbasi et al., 2006). A two-stage algorithm for robust RCPSP was used while minimize $C_{\text {max }}$, of the project as an acceptance threshold for second stage was carried out and then, in next stage, a set of 12 alternative robust predictive indicators was employed to maximize robustness of the project (Chtourou and Haouari, 2008).

RCPSPs can be considered as an NP-hard problem while more than one none-renewable resource is taken into account (Kolisch, 1996). There are also some other parameters of project complexity that should be noticed as other managerial factors (Castejón-Limas et al., 2011). Traditionally, many 
problems were solved using branch-and-bound algorithm (Sprecher, 2000), but heuristics and metaheuristics were then found as good ways of solving RCPSCPs.

Multi-mode resource constraint project scheduling problems (MRCPSP) are distinctive resourceconstraint problems where each activity can be carried out via different modes (regarding to technologies or material etc.). As consequence, the execution period (activity duration), resource requirement level and even the cash flow may be vary form a mode to another. The MPRCPSP problem was initially developed for minimizing the project makespan and was proved to be a NP-hard problem (Kolisch and Drexl, 1997). Węglarz et al. (2011) provided a wide research on literature of the multimode project scheduling. One of the most important issues in MRCPSP studies is associated with financial issues which can be considered in two ways of positive or negative cash flows. Positive cash flows are supposed to earn as scheduled milestones. Negative cash flows are referred to those expenses which must be spent for making positive cash flows (as human resource salary, equipment and machinery purchasing and maintenance costs, raw material providing etc.). In such models, cash flow can be influenced by activity due date, duration, resource requirements and also payment method which would influence on activity execution mode as well. GA was then used for solving a multi-criteria project portfolio selection problem when project interactions (in terms of multiple selection criteria) and preference information (in terms of the criteria importance) were considered (Yu et al., 2012).

Kolisch \& Drexl (1997) found that MRCPSP is NP-hard if more than one resource is considered. To come up with such problem, many heuristics and metaheuristics approaches have been applied so far. Yan et al. (2009) applied some heuristics to solve project scheduling problem in order to provide a quick response structure while encountering with maritime disasters. Laslo (2010) presented an integrated method using simulation for resource planning and scheduling to minimize scheduling dependent expenses. Kim et al. (2005) proposed a hybrid GA and fuzzy logic controller (FLC-HGA) to solve the resource-constrained multiple project scheduling problem (RC-MPSP). Their objectives were minimizing total project time and total tardiness penalty. Ke \& Liu (2010) used hybrid fuzzy set and GA to minimize total cost with completion time limits (see also Hartmann \& Briskorn (2010) Jarboui et al. (2008) used particle swarm optimization (PSO) to show the effectiveness of PSO for solving MRCPSPs.

\section{Maximizing Profit of the project}

Maximizing profit of projects is considered as an important objective in financial studies of scheduling problems. Profit of the project can be considered with many different styles. In some studies profit is expressed as net present value of the project. The idea of maximizing NPV was first proposed by (Russell, 1970). The proposed model was nonlinear without taking limitations of resources. They assumed activity on art (AOA) to present network charts. Elmaghraby \& Herroelen (1990) proposed an optimal-finder algorithm which includes resource constraints for maximizing NPV. Sung \& Lim (1994) proposed a two stage heuristic to maximize NPV of a RCPSP. They found that while difference between the due date and the minimum duration increases, the NPV gets more improved.

One of the most important issues in maximizing NPV is to consider positive or negative cash flows during scheduling process. Positive cash flows are supposed to earn as scheduled milestones. Negative cash flows are referred to those expenses which must be spent for making positive cash flows (as human resource salary, equipment and machinery purchase and maintenance costs and raw material providing). In such models, cash flow can be influenced by activity due date, duration, resource requirements and also payment method which will effect on determining activity execution mode as well.

Etgar et al. (1997) showed that resources beyond time limit can have significant effect on makespan of project. Meanwhile, De Reyck (1998) offered an algorithm based on both positive and negative cash 
flows. A lower and upper bound were considered for each activities where coupled with limited resources. Icmeli et al. (1993) discussed that adding resources limitations caused turning model into a non-polynomial model which cannot be solved easily by optimizing algorithms. Then, they considered discounted rate in their proposed model so that more cash flows would be earned in case of completing an activity in shorter period (RCPSPDCF). Afterward, many researchers have tried to solve the problem of maximizing net present value (NPV) while discount rate is taken into consideration. Baroum \& Patterson (1999) solved a RCPSPDCF model with 50 variables where only positive cash flows were considered. Afterward, Icmeli \& Erenguc (1994) used Tabu search (TS) algorithm for solving RCPSPDCF problem. They set penalty for activities later than the due date. Yang et al. (1993) developed statistical programming for solving RCPSPDCF problems while positive cash flows were taken into consideration. Moreover, Zhu \& Padman (1999) used TS for solving RCPSP-DCF problems. Mika et al. (2005) presented a model with the aim of maximizing NPV of project with taking discounted rate and also both renewable and non-renewable resources. They used hybrid of SA and TS to solve the problems. During the last decade, preemptive resource in scheduling problems have been more developed due to their impacts on making major delays through project lifecycle as well. Laslo (2010) proposed a method for minimizing total cost of executing project activities. Delgoshaei et al. (2014) used simulated annealing (SA) for maximizing NPV of the MRCPSP-DCF while discounted cash flows was taken into consideration. For this purpose a backward method was used to use the remained resources through the resource calendar of a schedule.

During the last decade, preemptive resource in scheduling problems has been more developed due to their impacts on making major delays through project lifecycle as well. Demeulemeester \& Herroelen (1996) presented an optimal solution for RCPSP while they considered preemptive resources in their model. Buddhakulsomsiri \& Kim (2006) discussed that considering pre-emption resources is vital while studying makespan of the project. Damay et al. (2007) applied linear programming algorithms for preemptive RCPSP studies while Ballestín et al. (2008) proposed heuristic for solving preemptive RCPSP. Seifi \& Tavakkoli-Moghaddam (2008) evaluated four payment methods during maximizing NPV and minimizing holding cost of completed activities in a MRCPSP. Peteghem \& Vanhoucke (2010) used GA to minimize makespan of MRCPSP while they considered preemptive resources which allow activity splitting through their research.

To the best knowledge of authors, the idea of maximizing profit of manufacturing projects in MRCPSPs while activity split is allowed and preemptive resources are taken into consideration, is less developed. To overcome such shortcoming, a multi-mode resource constrained scheduling problem with positive cash flows (MRCPSP-PCF) is developed. Then impact of activity split on preventing resource overallocation is examined. In this regard, a forward method is proposed which works based on positive cash flow and activity id priority rules to overcome the resource over-allocations that usually happen by scheduling resource constraint project.

\section{Research Methodology}

In this section, a mathematical scheduling model is developed with the aim of maximizing profit of scheduling resource constrained projects. The model considers multi-mode execution for each of the activities. Our aim is to survey how allocation of preemptive resources can change the activity scheduling and the effect on makespan of the project. In summary, we can mention the advantages of the proposed model as follows: Considering preemptive resources in maximizing profit of projects, considering multi-mode execution activities, considering activity splitting ability with respect of the predecessors. Main constraints are the resource capacity, fixed time of the planning. Only positive cash flow is considered, exact occurrence of all activities, and exact duration of each activity mode and exact cash flow for each activity mode are also taken into consideration. The properties of the developed model are shown as: 
1. Model is presented in Activity on Node (AON) structure.

2. Progress Payment (PP) is selected as the payment model.

3. Resources are considered preemptive.

4. Activities are allowed to be split through the planning horizon.

5. The preemptive resources have limited capacities.

6. In this study, positive cash flows are considered as weight factor of each activity.

7. Activities can be executed in different modes. While a mode selected to an activity, the same mode must be used during executing of the activity.

8. Activities are allowed to move only in their free-float time.

9. All improving movements will carry out in forward mode.

\subsection{Problem Definitions}

In order to classify models easily, in this section we define problems with a unique code as below:

$n|m| k \mid C T$

In this classification, $n$ presents number of activities, $m$ is number of activity mode, $k$ is number of resource types and $C T$ is time horizon of the project.

\section{Subscript}

Subscripts used in the model are considered as follows:

$i=$ number of activities which is a $1 * \mathrm{n}$ matrix $\left(\left[\begin{array}{lll}1 & . \mathrm{N}\end{array}\right]_{1 \times \mathrm{n}}\right)$

$k=$ number of resource types which is a $1 * \mathrm{~m}$ matrix $\left([1 \ldots \mathrm{K}]_{1 \times \mathrm{k}}\right)$

$t=$ available time horizon for production $(\mathrm{t}=1,2 \ldots \mathrm{T})$

$m=$ number of modes of performance $\left([1 \ldots \mathrm{M}]_{1 \times \mathrm{m}}\right)$

\section{Parameters}

The list of parameters and notations is as follows:

Resource_Capacity: illustrates available resource in sub periods:

$$
\left[\begin{array}{lll}
R C_{1} & \ldots & R C_{k}
\end{array}\right]_{1 * k}
$$

As a result, number of in-process activities that queued in a waiting list to be served by a preemptive resource can be expressed using below formula:

$$
R C_{k}=R_{k}-\sum_{i=1}^{n} r_{(i, k)} * y_{(i, m, t)} ; \forall(k \in K) \&(t \in T H)
$$

Activity_time: shows duration of each activity considering different execution modes.

$$
\left[\begin{array}{ccc}
11 & \cdots & 1 n \\
\vdots & \ddots & \vdots \\
m 1 & \cdots & m n
\end{array}\right]_{m * n}
$$

Activity_sequence matrix is used in mathematical programming to show precedence relations between activities.

$$
\left[\begin{array}{ccc}
11 & \cdots & 1 n \\
\vdots & \ddots & \vdots \\
n 1 & \cdots & i n
\end{array}\right]_{n * n}
$$

$C F(i, m)=$ positive cash flow of activity $i$ while it performs in mode $m$

$\mathrm{r}(\mathrm{i}, \mathrm{k})=$ usage amount of resource type $k$ for activity $i$

$R(k)=$ available level of resource type $k$ 
$D(i, m)=$ duration of Activity $i$ while it performs in mode $m$

$\mathrm{TH}=$ time horizon of the project

\section{Decision Variables}

$y(i, m, t)=\left\{\begin{array}{lc}1 & \text { if activity } i \text { performs on mode } m \text { during sub period } t \\ 0 & \text { otherwise }\end{array}\right.$

$E S_{i}=$ Early start of activity $i$

\section{Mathematical Model}

As mentioned in the previous parts, studying an MRCPSP problem is the major objective of this paper. We supposed to have $n$ activities on an AON network. Hence, Mathematical model is now written as follows:

$\operatorname{Max}: \sum_{t=1}^{T H} \sum_{i=1}^{n} \sum_{m=1}^{M} y_{(i, m, t)} \cdot C F_{(i, m, t)}$

S.T:

$$
\begin{aligned}
& E S_{i}=\min _{t=1: T H}\left(\left\{t .\left(y_{(i, m, t)}-y_{(i, m, t-1)}\right) \mid y_{(i, m, t-1)}=0\right\}\right) \forall i=1, \ldots, n \\
& E S_{i}>\max _{t=1: T H}\left\{t \cdot y_{(j, m, t)} \mid y_{(j, m, t)}=1\right\} ; \forall(i, j) \in P_{i} \\
& E S_{1}=1 \\
& \max _{t=1: T H}\left\{t \cdot y_{(n, m, t)} \mid y_{(n, m, t)}=1\right\} \leq T H \\
& \sum_{t=1}^{T H} y_{i, m, t}=d_{i, m} ; \forall i=1, \ldots, n \& m=1, \ldots, M \\
& \sum_{m=1}^{M} y_{i, m, t}=1 ; \forall i=1, \ldots, n \& t=1, \ldots, T H \\
& \sum_{i=1}^{n} \sum_{m=1}^{M} r_{i, k} \leq R_{k} ; t=1, \ldots, T \& k=1, \ldots, K \\
& E S_{i}=\text { integer } \geq 0 \\
& y_{i, m, t}=\text { bin }
\end{aligned}
$$

For the proposed model, maximizing profit of a multi-mode project by considering renewable resources is considered as the main objective. The objective function is written in a way that it can easily calculate profit of the project every time slots using the progress payment method.

First constraint in this model is defined for determining early start of activities, which guarantees the solving algorithm to stay feasible during searching process. Using the term $\min _{t=1: T H}\left(\left\{t .\left(y_{(i, m, t)}-y_{(i, m, t-1)}\right) \mid y_{(i, m, t-1)}=0\right\}\right)$ helps identifying the real early start of activities when they are taken apart by the solving algorithm to avoid encountering with resource over-allocation. The reason of using split ability for some activities will be explained in section 3.4. It is important to know that using standard definition of early start of activities (which is $E S_{i} \geq E S_{j}+d_{j}$ if $j$ is direct predecessor of $i$ ) is not appropriate for MRCPSPs while activity splitting is allowed since it causes 
wrong calculation. To explain more, suppose it is decided to calculate $E S$ for activity $D$ with and without activity splitting permission (Fig. 1).
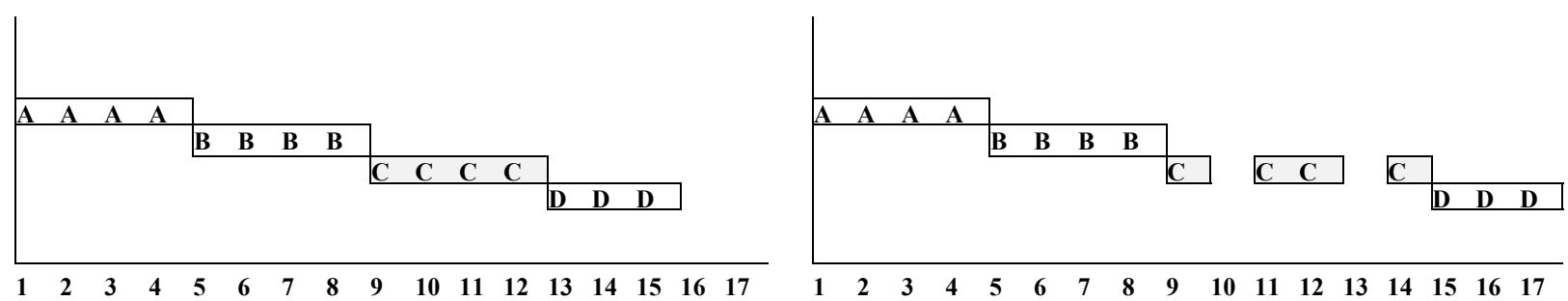

Fig. 1. Comparing Different Styles of Calculating ES with and without Activity Splitting (Left to Right)

In the left Gantt of Fig. 1, while splitting is not allowed, $E S_{D}$ can be calculated correctly by using the mentioned formula $\left(E S_{D}=E S_{C}+d_{C}\right)$. But, as seen, calculating early start of activity $D$ while activity splitting is allowed (right figure) is not 13 anymore since activity $C$ is split two times in days 10 and 13 and cannot be finished earlier than the end of day 14 . Consequently, activity $D$ cannot be started sooner than the day 15 . Therefore, to prevent such error, a new formula is developed for calculating $E S$ of each activity:

$$
E S_{i}=\min _{t=1: T H}\left(\left\{t .\left(y_{(i, m, t)}-y_{(i, m, t-1)}\right) \mid y_{(i, m, t-1)}=0\right\}\right)
$$

Second constraint ensures that activity will not be started before the early finish of its predecessors. Similar to the logic used for calculating early start of activities while activity splitting is allowed, early standard finish formula $\left(E F_{i}=E S_{i}+d_{i}\right)$ cannot be used here as there might be some none working days that happens by the solving algorithm to avoid resource over-allocating. Therefor a formula is developed for calculating the early finish of an activity which is able to consider the idle times among the lifecycle of an activity:

$$
E F_{j}=\max _{t=1: T H}\left\{t . y_{(j, m, t)} \mid y_{(j, m, t)}=1\right\}
$$

The third constraint is developed to set a logic starting day for any project. Since the model is considered as a real time model which must be finished before a due date, the fourth constraint is set for ensuring that the early finish of the last activity will not exceeded than the due date. For considering splitting ability, the solving algorithm must be able to divide an activity to the smallest period slots (1 day) to schedule them throughout the calendar of the project to avoid resource over-allocation. It may cause passing the initial duration of activities in dynamic process of scheduling. To avoid this mistake, the fifth set of constraints are set which guarantee that the number of working days for each activity will not exceeded than the original duration of an activity (considering its execution mode). The sixth sets of constraints are set to keep a selected execution mode of an activity throughout its execution period. The seventh sets of constraints are to avoid over-allocating the resources in every single period slot throughout the project. The last two sets of constraints are logic constraints which show the domain of the variables.

\section{Solving Algorithm}

In this section, a new forward method is proposed for scheduling activities through planning horizon while maximum amount of available resources are restricted and activity splitting is allowed. Elmaghraby \& Herroelen (1990) dealt with the demonstration of NP-hard in its RCPSP models. Zhou 
\& Askin (1998) also reported that Resource-constrained project scheduling problems with cash flows (RCPSPCF) are complex and combinatorial optimization problems and should be solved by heuristics. As mentioned in above, if MRCPSP issues enjoy more than one resource, they will be considered strongly as part of NP-hard issues. Since nonlinear with exponential status is considered as target function of our desired model and with due observance to this fact that some of constraints enjoy nonlinear status like constraints of the first group, we can come to this conclusion that the proposed model is NP-hard. There is also another reason for considering the mentioned model as NP-hard that is due to the number of the basic solutions that increases extremely while we increase the number of the variables. For example consider a simple model with 10 variables and 3 resources with 75 constraints that includes $C=85 ! /(10 ! 75 !)=3,129,162,672,636$ solutions as basic feasible and basic infeasible solutions together. Therefore, if the number of the variables increases extremely, optimal solution algorithms obviously cannot able to find the Optimum Basic solution (Delgoshaei et al., 2016).

The main concept of the proposing method is inspired from Delgoshaei et al. (2015) as their research is similar to this research in terms of scheduling constraint resource activities. The following flowchart shows the mechanism of the proposed method (Fig. 2):

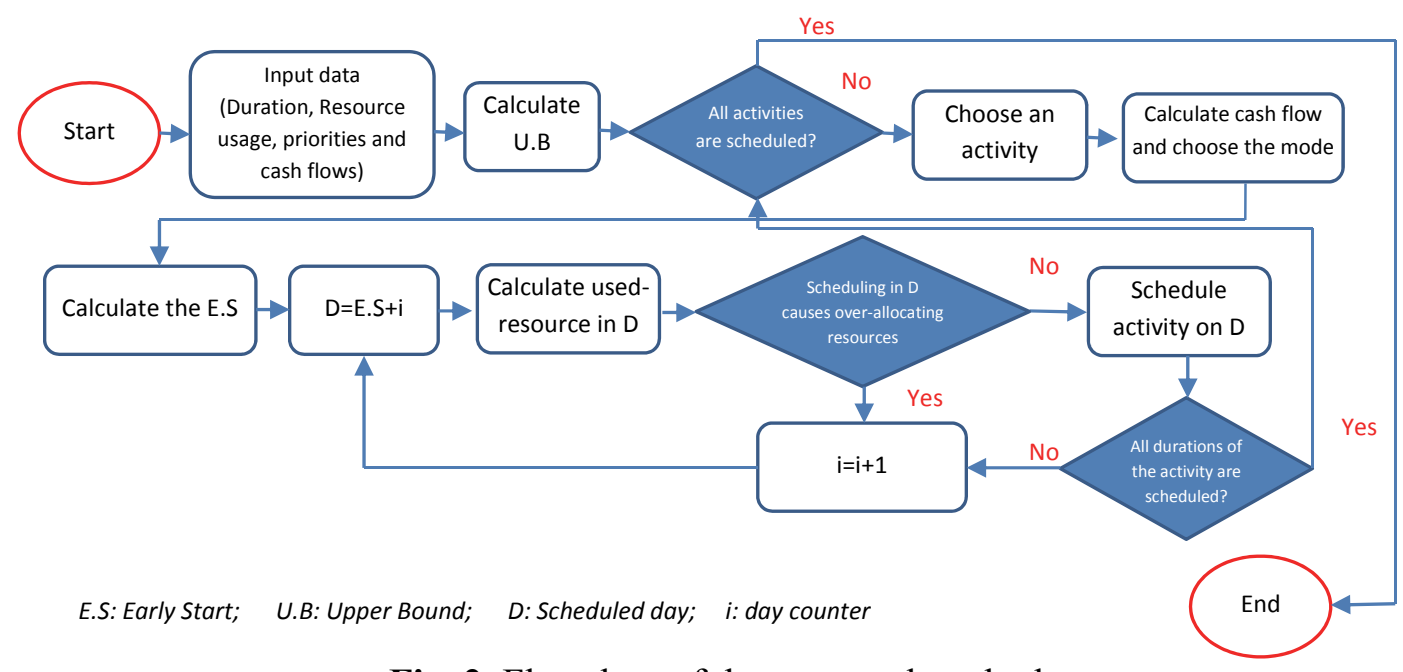

Fig. 2. Flowchart of the proposed method

The mechanism of the proposed method is based on forward programming of activities considering activity priorities.

\section{Calculating an Upper feasible bound}

The procedure starts by finding an initial feasible solution to the problem from an upper bound for each activity that meets the feasible priorities to each activity but not necessarily the maximum objective function value (or a set of activities that can make a schedule). In this step we do not pay attention to the profit of the project. The upper bound for the cycle can be found from the below equation:

$$
U B=\sum_{l=1}^{n} \max d_{i, m} ; \text { for all }(i, m) \text { belongs to Product_sequence matrix }
$$

The upper bound draws a feasible solution space for searching algorithm as none of the schedules passes the UB. Hence, the solutions will stay feasible throughout the searching process in terms of the time horizon.

\section{Tournament list and searching neighbors}


The function of this operator is to find the best activity which is possible to schedule and, at the same time, can maximize the profit of the project. In this manner for each slot period, the algorithm will create a list of the activities which can be started or continued respecting to their priority lists. Then choosing the best member is based on following two rules respectively:

Weight Rule: an activity will be chosen according to maximum weighted factor, here is cash flow. Resource availability: if resource becomes over allocated, algorithm will find the next days for allocation.

Suppose $\mathrm{T}=\mathrm{t}$ :

1) Find $\alpha \in F A \mid \sum_{t=1}^{T H} y_{\alpha, m, t}=d_{\alpha, m} ; \forall k \in i$ (List finished activities)

2) If all $\beta \in P(\alpha, \beta)$, then Tournament. list ${ }_{\alpha}=\alpha$ (Find the list of activities that can be started)

3) $\gamma=\max _{\text {Tournament.list }}\left(C F_{l}\right)$ (Find the max $C F$ in the tournament list)

4) If $r_{\gamma, k} \leq R_{k} ; \forall T=t$ and $r \in K$, then $y_{\gamma, m, t}=1$ (Check if there is enough resource for activity $i$ to be set. If not eliminate i from tournament list and got o step 4)

Note that split usually happens in parallel routes in networks or when activity precedence is start to start. The proposed method, respecting to activity priorities, consists of scheduling more valuable activities sooner which cause gaining maximum profit of the project, and filling the remained resources by other activities or even by replacing more weighted activities with current activities.

\section{Solution representing:}

A unique solution representing scheme is considered by developing 4 matrixes where the first matrix shows the execution of activities in the time horizon of the project, the second matrix indicates the consumed resources in the every working days and third matrix shows the cumulative used resource throughout the project lifecycle (Fig. 3).

\begin{tabular}{cccccc} 
Gantt Chart & Consumed resources & Cumulative allocated resource \\
\hline$\left[\begin{array}{llllllllllll}1 & 1 & 0 & 0 & 0 & 0 \\
0 & 0 & 1 & 1 & 1 & 0\end{array}\right]_{i * T H}$ & {$\left[\begin{array}{cccccccccc}15 & 12 & 0 & 0 & 0 & 0 \\
0 & 0 & 22 & 20 & 36 & 0\end{array}\right]_{k * T H}\left[\begin{array}{cccccc}15 & 27 & 0 & 0 & 0 & 0 \\
0 & 0 & 22 & 42 & 78 & 0\end{array}\right]_{k * T H}$}
\end{tabular}

Fig. 3. A representing scheme sample

\section{Fitness Function Operator}

The objective function of the model will be used as fitness function operator.

$$
\sum_{t=1}^{T H} \sum_{i=1}^{n} \sum_{m=1}^{M} y_{(i, m, t)} \cdot C F_{(i, m, t)}
$$

After generating a list of possible movements of different activities for a specific day, the objective function of each solution will be evaluated to check if it can improve the observed profit so far. If so, it will be considered as an approved movement.

a) Suppose $\mathrm{X}_{\mathrm{k}}^{\mathrm{itr}}\left(\mathrm{x}_{1}, \mathrm{x}_{2}, \ldots, \mathrm{X}_{\mathrm{i}} ; \mathrm{r}_{1}, \mathrm{r}_{2}, \ldots, \mathrm{r}_{1} ; \mathrm{R}_{1}, \mathrm{R}_{2}, \ldots, \mathrm{R}_{\mathrm{i}}\right)$ is the $\mathrm{k}^{\text {th }}$ possible movement in itr $^{\text {th }}$ iteration.

b) If $\mathrm{F}\left(\mathrm{X}_{\mathrm{k}}^{\mathrm{itr}}\right) \geq \min \left(\mathrm{F}\left(\mathrm{X}_{1}^{\mathrm{itr}}\right), \mathrm{F}\left(\mathrm{X}_{2}^{\mathrm{itr}}\right), \ldots, \mathrm{F}\left(\mathrm{X}_{\mathrm{k}-1}^{\mathrm{itr}}\right)\right) ; \forall \mathrm{k} \in$ Tournament. list

c) Then, $y_{k, m, t}=1$ 


\section{Stopping criteria}

The program will be terminated when at least one of these conditions happen:

1. All activities are scheduled.

2. Activities are scheduled in a way that there are no remain resources during time horizon which means there is no improvement in current solutions.

a) Suppose activity $\alpha$ is decided for being scheduled from day $t$ onward.

b) If $r_{k, t}>R_{k, t}-\sum_{i=1}^{n} r_{k, t} \cdot y_{i, m, t}$ for all $t \geq E S_{\alpha}$

Then Tournament. list ${ }^{\mathrm{itr}}=\varnothing$ for next iteration

\section{Results and Discussion}

To examine and verify the impact of preemptive resources to net present value of a resource-constraint scheduling problem, a case study with 30 activities will be illustrated in details first. Then a number of large scale experiments will be solved to examine the effectiveness of the proposed method. The problems will be solved using MATLAB R2011® which is installed on a Core i7 laptop that is supported by $8 \mathrm{Mb}$ RAM. Each problem is allowed the maximum time based on upper bound introduced in Eq. (15). Note that the proposed model is Np-hard and cannot be solved within reasonable time optimally. Thus, we consider a feasible interval for the optimal objective function value (OFV). At such a point, the user may choose to interrupt the solver and go with the current best solution in the interest of saving on additional computation time.

In this experiment, 30 activities are considered. Number of modes is 4 and number of the limited resources is 2. The network of this experiment is shown by Fig. 4. Rest of the required data is presented by Table 1 .

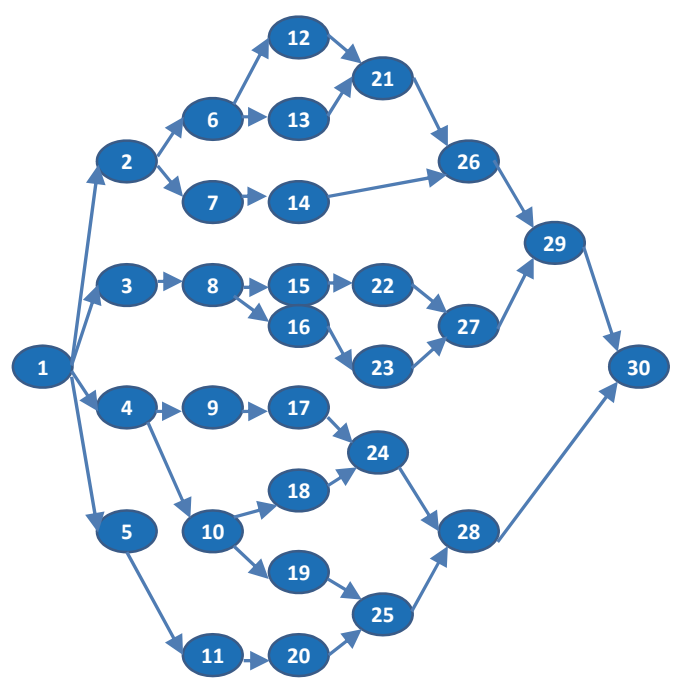

Fig. 4. Network diagram for the experiment

This experiment is also solved in two modes of relaxed and limited resource constraints. Fig. 5 and Fig. 6 show the proposed Gantt charts for relaxed and limited resource modes respectively. The calculated upper bound for this experiment is 164 working days. It is observed that the limited resources cause the makespan of the project to be increased from 45 working days in the first mode to 46 working days in the second mode. The Gantt chart in Fig. 6 shows that activity 23 and 27 are decided to be taken apart by the algorithm to increase the resource usage. 


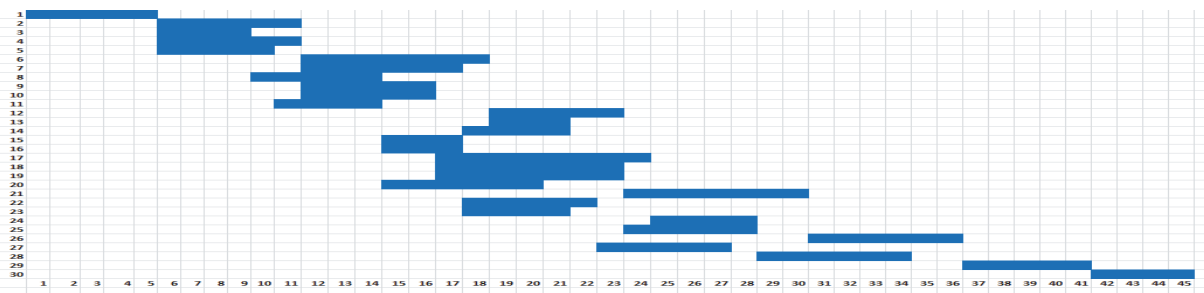

Fig. 5. Gantt chart of the experiment relaxed resource constraints

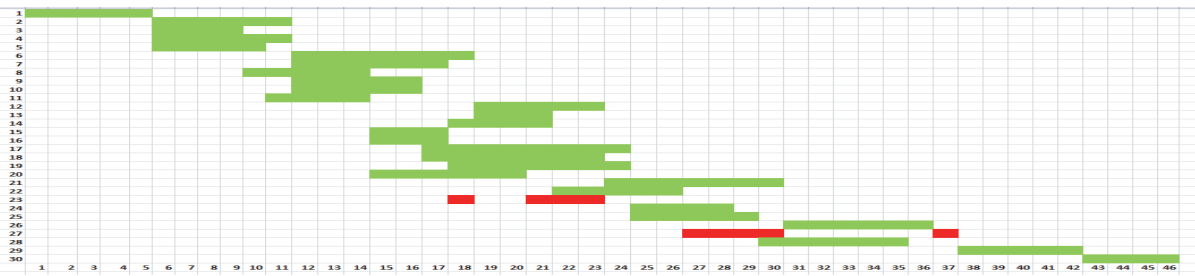

Fig. 6. Gantt chart of the experiment after using the proposed method

The cumulative resource usages throughout the project calendar for each of the resources are shown in Fig.7. As seen for each of the resources, the slope of resource usage graphs after using the proposed forward method is smoothed. The S-curve of the graphs shows that the schedule is safe to be used.
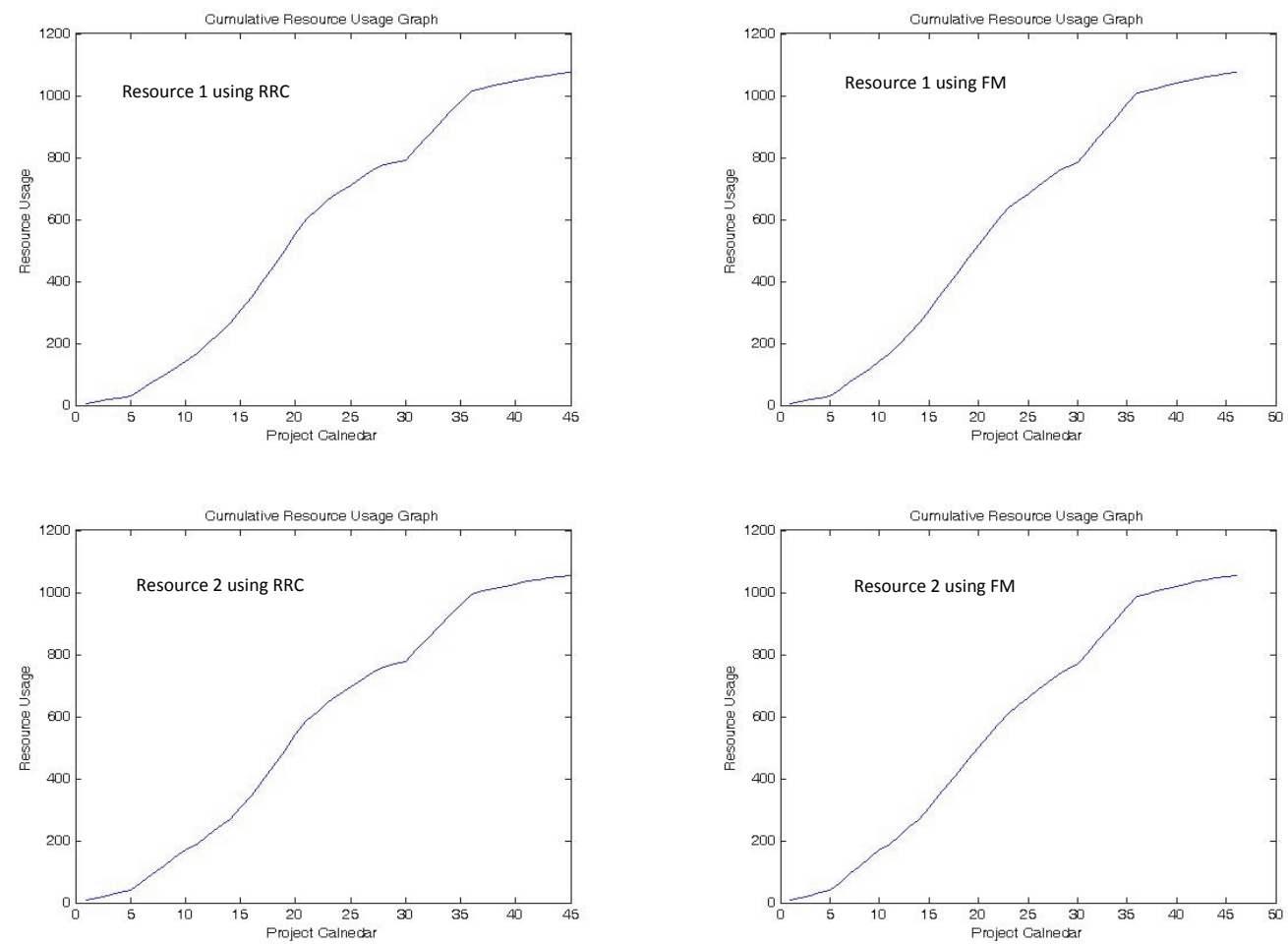

R.R.C: Relaxed Resource Constraint

F.M: Forward Method

Fig. 7. Comparing the cumulative resource usage while using R.R.C and F.M methods

The resource usage through the resource calendar is shown by Fig. 8. The days 17, 18, 19, 20 and 21 are reported as over-allocated working days where the number of available resources is insufficient to complete the activities that are scheduled in these days. In order to modify the over-allocation in this case, the algorithm decided to take apart activities number 23 and 27 for the mentioned days. Consequently, the activity 23 is split in days 19 and 20 and activity 27 is taken apart in days 31 to 36 . Similar to other experiments, in this experiment after using the forward method, none of the working days are reported over-allocated. 

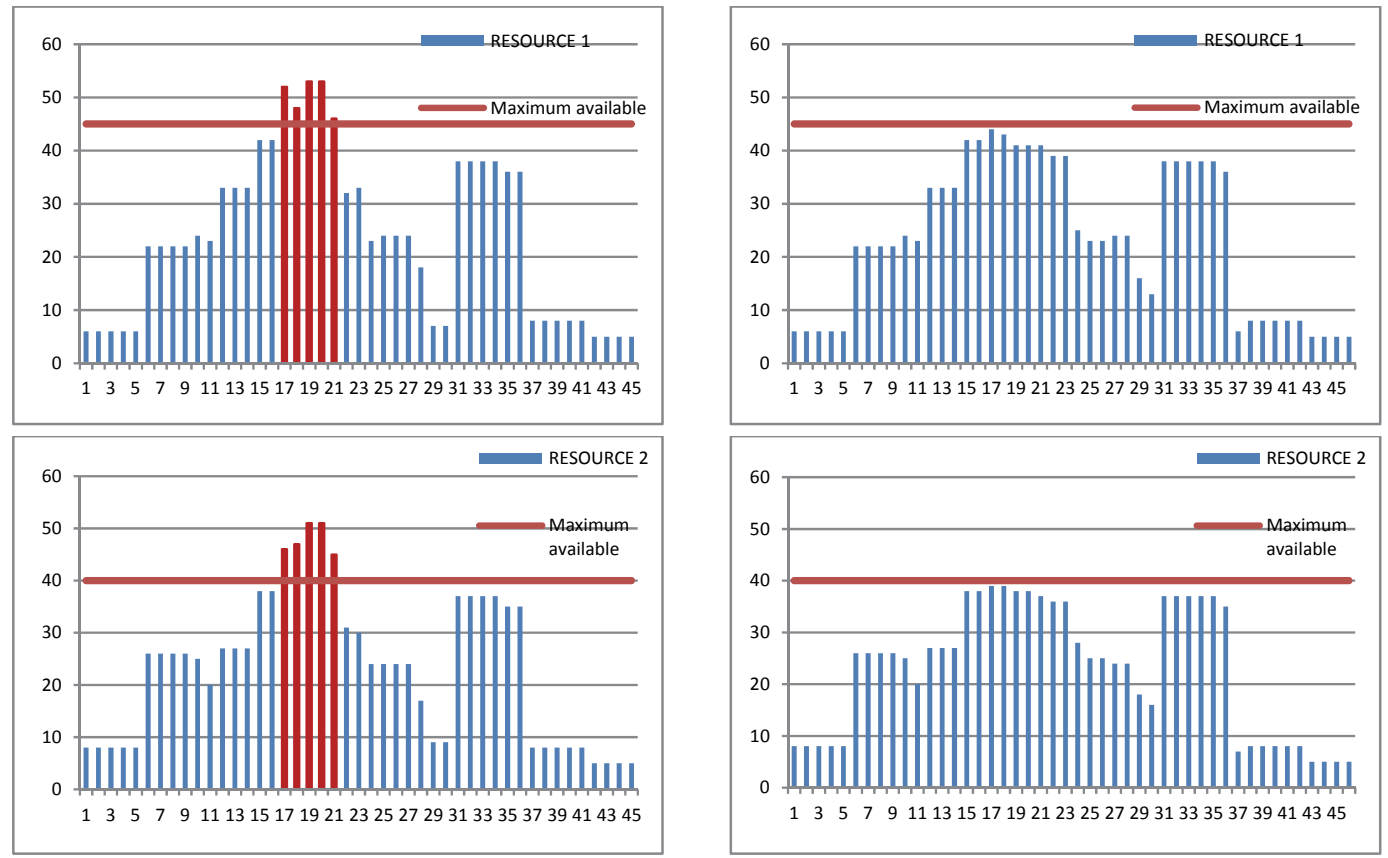

Fig. 8. Daily usage of the resources before and after using the proposed method throughout the calendar of the project

\section{Solving experiments gathered from the literature}

To examine the proposed approach, 10 series of small, medium and large scale examples are designed and solved with 5, 6, 13, 15, 18, 20, 25, 30, 40 and 50 variables.

\section{Table 1}

Results of solving experiments derived from the literature

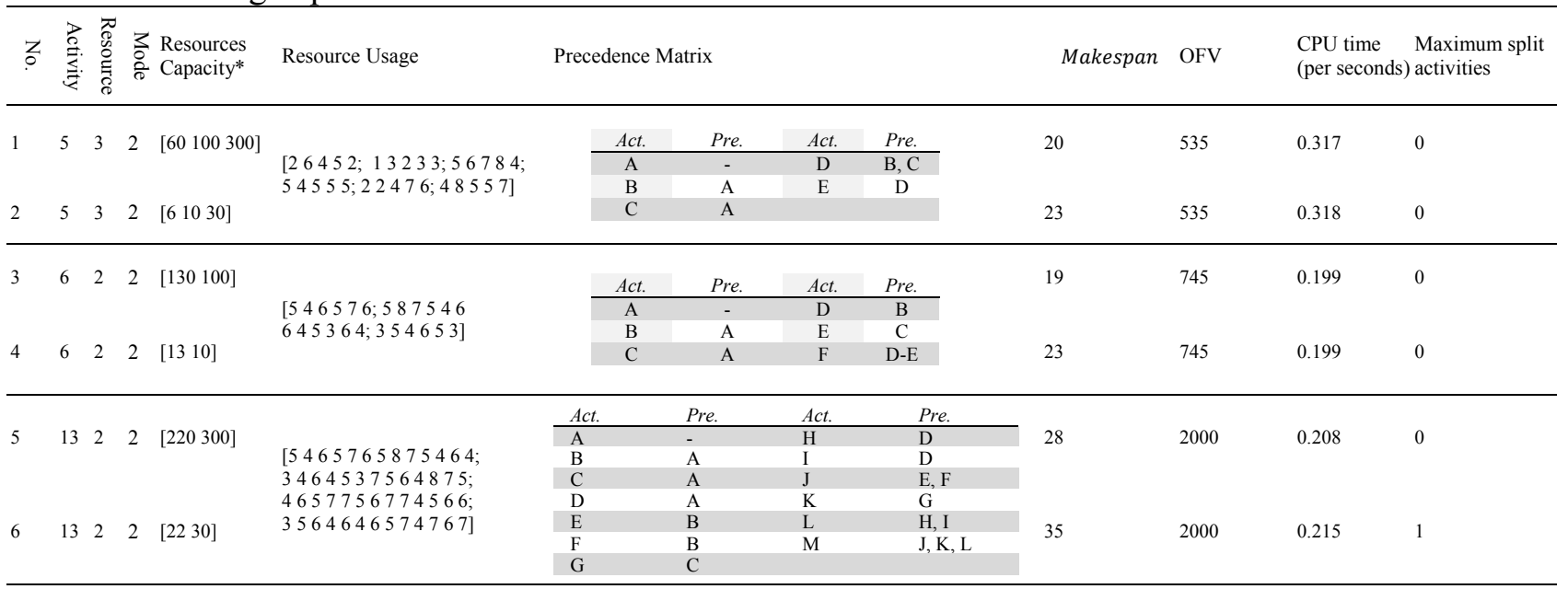


For evaluating the efficiency of proposed model each example is solved under two conditions where all the criteria are considered the same but resource availability. The results, then, were checked with the results of forward serial programming method (Table 1, Table 2 and Table 3 ).

\section{Table 2}

Results of solving experiments derived from the literature (Continued)

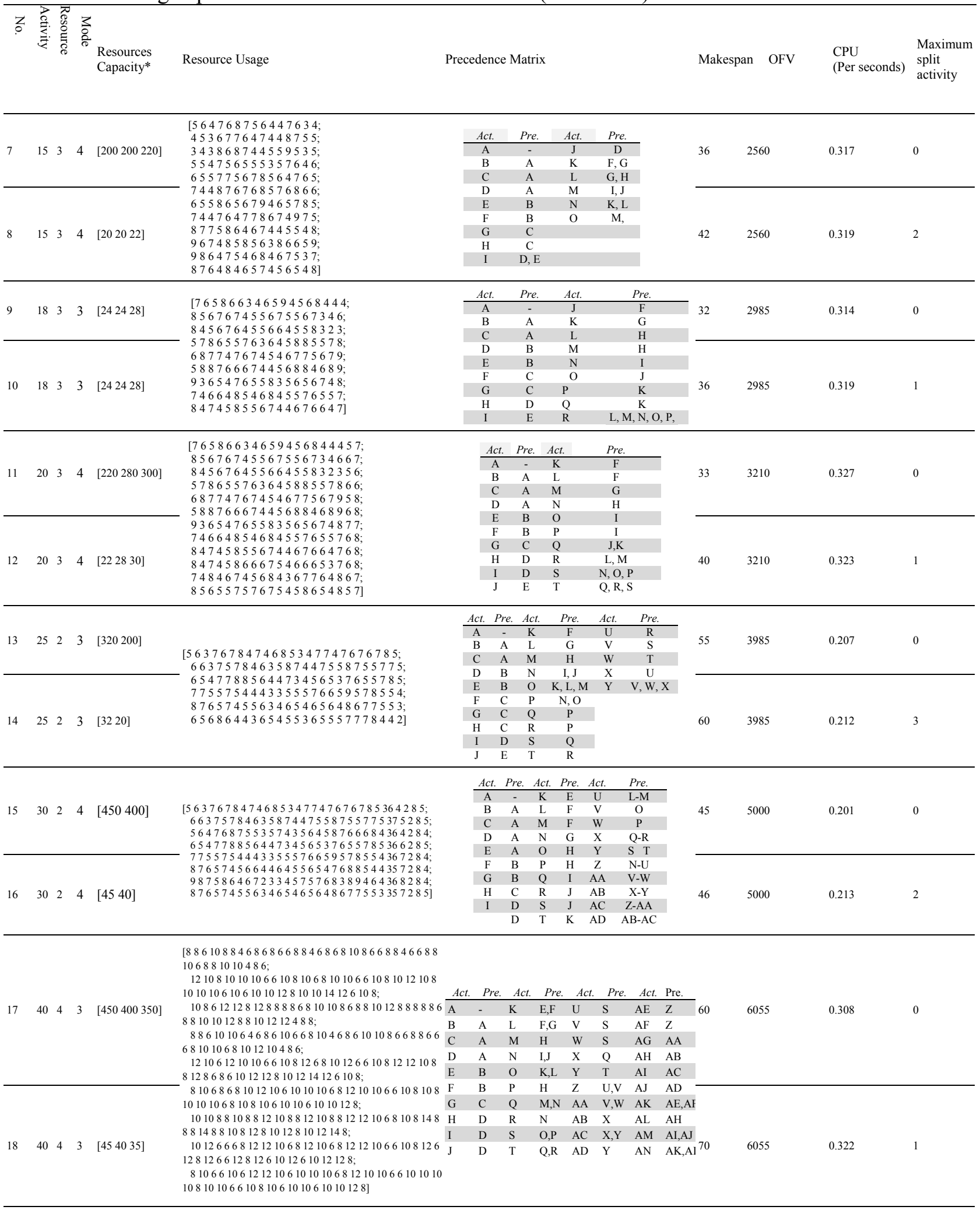


Table 3

Results of solving experiments derived from the literature (Continued)

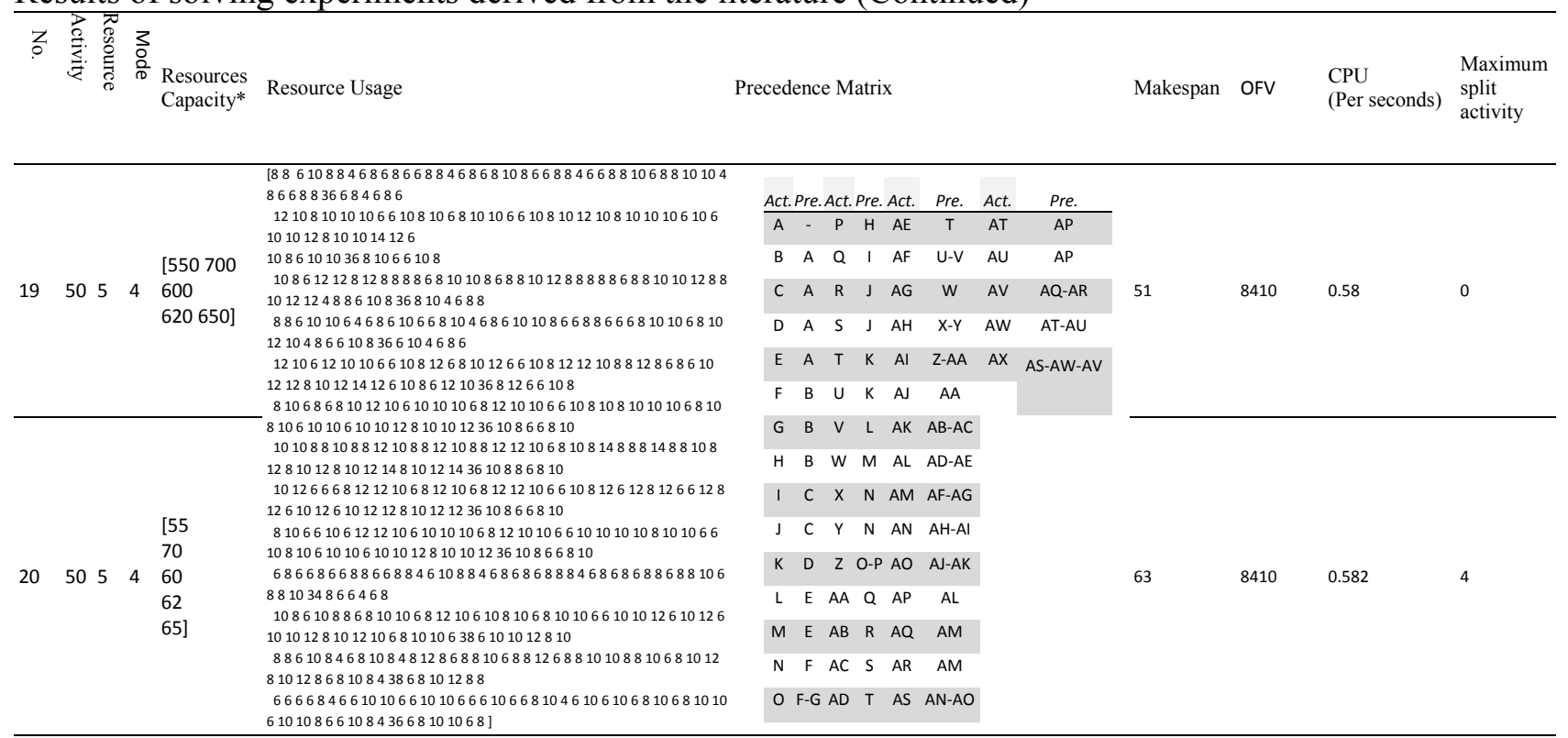

Results that are shown in Table 1 indicate that for small scale problems the algorithm can avoid activity split by postponing activities that are scheduled in over-allocated days. However by increasing the number of activities and complicating the precedence matrix, it is shown that the amount of time that activities are split to modify over-allocation increased (Table 2 and Table 3 ).

\section{Measuring the completion time with makespan index}

In this section, in order to evaluate how limited resources influence the makespan of the project, a new index is developed:

Makespan. index $=100 *\left(\frac{\text { Makespan observed by forward programing method }}{\text { Makespan while resource limits are relaxed }}-1\right)$

Fig. 9 shows the results of calculating Equation 15 for the experiments.

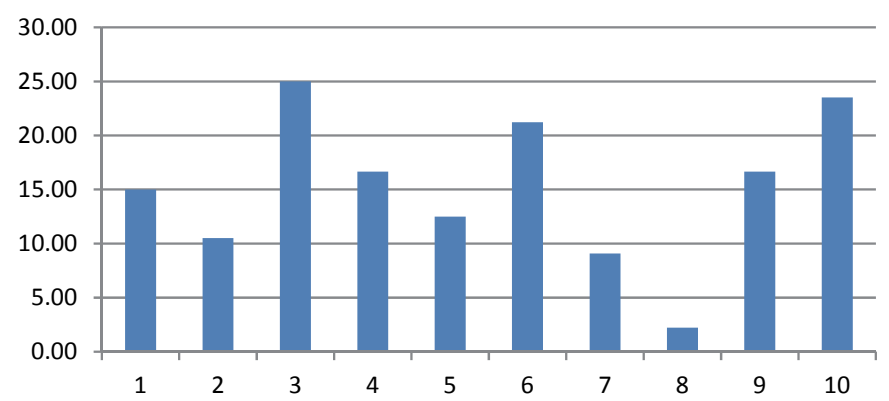

Fig. 9. Makespan index graph for the solved experiments

The results in Table 4 shows that although the proposed method could avoid over-allocating of activities, but at the same time limited resources can cause delay in makespan in a value between $2.22 \%$ and $25 \%$. Fig. 10 shows that in all the studied cases, the observed makespan are smaller than UB. UB is considered as upper limit for the makespan of a project and any value larger than this can thus be considered as an infeasible solution. 
Table 4

Results gained after scheduling experiments

\begin{tabular}{|c|c|c|c|c|c|c|c|c|}
\hline \multirow[b]{2}{*}{ No. } & \multirow[b]{2}{*}{$\begin{array}{l}\text { Number of } \\
\text { Activities }\end{array}$} & \multirow[b]{2}{*}{$\begin{array}{l}\text { Number of } \\
\text { Resources }\end{array}$} & \multirow[b]{2}{*}{$\begin{array}{c}\text { Number of } \\
\text { execution modes }\end{array}$} & \multirow[b]{2}{*}{ Resource level } & \multicolumn{3}{|c|}{ Method } & \multirow[b]{2}{*}{ M.S.I\% } \\
\hline & & & & & U.B & $\begin{array}{c}\text { Normal } \\
\text { scheduling }\end{array}$ & $\begin{array}{c}\text { Froward } \\
\text { programming } \\
\text { method }\end{array}$ & \\
\hline 1 & 5 & 3 & 2 & {$[6,10,30]$} & 23 & 20 & 23 & 15.00 \\
\hline 2 & 6 & 2 & 2 & {$[13,10]$} & 31 & 19 & 21 & 10.53 \\
\hline 3 & 13 & 2 & 2 & {$[22,30]$} & 78 & 28 & 35 & 25.00 \\
\hline 4 & 15 & 3 & 4 & {$[20,20,22]$} & 90 & 36 & 42 & 16.67 \\
\hline 5 & 18 & 3 & 3 & {$[24,24,28]$} & 93 & 32 & 36 & 12.50 \\
\hline 6 & 20 & 3 & 4 & {$[22,28,30]$} & 112 & 33 & 40 & 21.21 \\
\hline 7 & 25 & 2 & 3 & {$[32,20]$} & 136 & 55 & 60 & 9.09 \\
\hline 8 & 30 & 2 & 4 & {$[45,40]$} & 164 & 45 & 46 & 2.22 \\
\hline 9 & 40 & 3 & 3 & {$[45,40,35]$} & 205 & 60 & 70 & 16.67 \\
\hline 10 & 50 & 5 & 4 & {$[55,70,60,62,65]$} & 275 & 51 & 63 & 23.53 \\
\hline
\end{tabular}

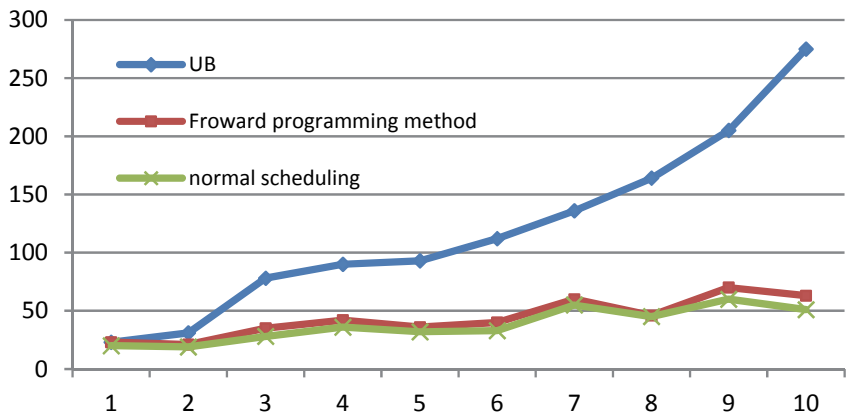

Fig. 10. Comparing the makespan in normal scheduling and forward serial programing for the solved experiments

Table 5

Over-allocated days in normal and modified schedules observed before and after using the method

\begin{tabular}{|c|c|c|c|c|c|c|c|c|c|c|}
\hline No. & 1 & 2 & 3 & 4 & 5 & 6 & 7 & 8 & 9 & 10 \\
\hline $\begin{array}{l}\text { Over allocated days (Normal } \\
\text { Scheduling) }\end{array}$ & {$[3,3,0]$} & {$[4,0]$} & {$[5,0]$} & {$[7,8,7]$} & {$[6,5,2]$} & {$[12,7,6]$} & {$[4,11]$} & {$[5,5]$} & {$[7,13,24]$} & {$[22,15,21,22,17]$} \\
\hline $\begin{array}{l}\text { Over-allocated days (Forward } \\
\text { programming method) }\end{array}$ & {$[0,0,0]$} & {$[0,0]$} & {$[0,0]$} & {$[0,0,0]$} & {$[0,0,0]$} & {$[0,0,0]$} & {$[0,0]$} & {$[0,0]$} & {$[0,0,0]$} & {$[0,0,0,0,0]$} \\
\hline
\end{tabular}

Table 5 compares the number of over-allocated days of each of the resources through its calendar before and after using the method. The results show that in any case studies the over-allocation is observed (Fig. 11).

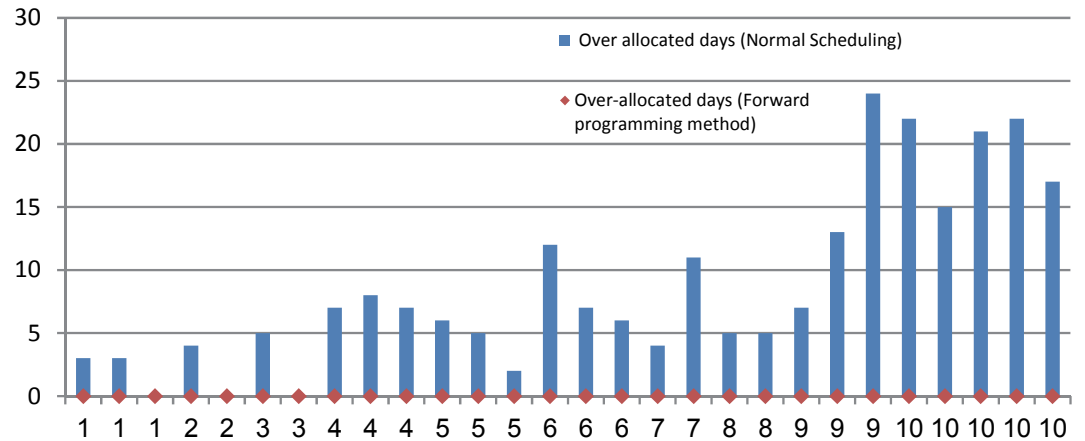

Fig. 11. Comparing number of over allocated days for the solved experiments

\section{Validating the proposed method}

In this section, the data of a real project is used to validate the performance of the proposed method. The scope of the project includes electrical, piping and HVAC lines and installing the air washer 
machines. The project is executed in Tehran, Iran in 2012. The project general information is shown by Table 6 .

\section{Table 6}

General information of the project

\begin{tabular}{ll}
\hline Employer & IRANKHODRO Company \\
Consulting & Energy Consulting Engineers Company \\
\hline Contractor & Technaab Engineering Company \\
Period of Execution & 4.5 months \\
Project Scope & HVAC, Piping, Electrical \\
Project Location: & Iran Khodro Company, Tehran (20,000 Square meters) \\
\hline Executing Period & December 2012 to May 2013 \\
\hline
\end{tabular}

The activity information is shown by Table 7 . The required resources for executing each of the activities are shown in Table 8.

\section{Table 7}

Activity information

\begin{tabular}{|c|c|c|c|}
\hline ID & Activity & Number of the modes & Duration \\
\hline 1 & Shop preparedness and mobilization & 1 & $\lceil 7 \mathrm{M}\rceil$ \\
\hline 2 & Trench & 2 & $\lceil 710\rceil$ \\
\hline 3 & Installing supports for ducts & 2 & {$\left[\begin{array}{ll}20 & 25\end{array}\right]$} \\
\hline 4 & Installing ducts & 1 & {$\left[\begin{array}{ll}15 & 20\end{array}\right]$} \\
\hline 5 & Installing coverage for ducts & 1 & {$\left[\begin{array}{ll}10 & 20\end{array}\right]$} \\
\hline 6 & Install piping tray & 2 & $\left\lceil\begin{array}{ll}10 & 12\end{array}\right]$ \\
\hline 7 & Installing cable trunk & 2 & $\left\lceil\begin{array}{lll}10 & 12\end{array}\right]$ \\
\hline 8 & Install cable tray & 2 & $\left\lceil\begin{array}{lll}10 & 14\end{array}\right]$ \\
\hline 9 & Water piping & 1 & $\lceil 7 \mathrm{M}\rceil$ \\
\hline 10 & Return Piping & 1 & {$[7 \mathrm{M}]$} \\
\hline 11 & Drainage piping & 1 & [3 M] \\
\hline 12 & Floor drains & 1 & $\lceil 2 \mathrm{M}\rceil$ \\
\hline 13 & Cabling & 2 & {$\left[\begin{array}{ll}10 & 14\end{array}\right]$} \\
\hline 14 & Installing power supply & 1 & {$[4 \mathrm{M}]$} \\
\hline 15 & Structure of the air washer 1 & 2 & {$\left[\begin{array}{ll}10 & 15\end{array}\right]$} \\
\hline 16 & Structure of the air washer 2 & 2 & {$\left[\begin{array}{ll}7 & 14\end{array}\right]$} \\
\hline 17 & Install air washer 1 & 1 & $\lceil 3 \mathrm{M}\rceil$ \\
\hline 18 & Install air washer 2 & 1 & $\lceil 3 \mathrm{M}\rceil$ \\
\hline 19 & Connect cables and pipes of air washer 1 & 1 & [1 M] \\
\hline 20 & Connect cables and pipes of air washer 1 & 1 & {$[1 \mathrm{M}]$} \\
\hline 21 & Re-installing lightning cables & 1 & [3 M] \\
\hline 22 & Re-installing lightning lamps & 1 & {$[2 \mathrm{M}]$} \\
\hline 23 & Testing and site delivery & 1 & {$[7 \mathrm{M}]$} \\
\hline
\end{tabular}

\section{Table 8}

Resource usage of activities

\begin{tabular}{|c|c|c|c|c|c|c|}
\hline ID & Activity & Simple worker & Electrical worker & Electrical Technician & Mechanical worker & Mechanical Technician \\
\hline 1 & Shop preparedness and mobilization & 5 & 2 & 1 & 2 & 1 \\
\hline 2 & Trench & 2 & 0 & 0 & 2 & 1 \\
\hline 3 & Installing supports for ducts & 2 & 0 & 0 & 3 & 1 \\
\hline 4 & Installing ducts & 2 & 0 & 0 & 3 & 1 \\
\hline 5 & Installing coverage for ducts & 1 & 0 & 0 & 2 & 1 \\
\hline 6 & Install piping tray & 2 & 0 & 0 & 3 & 1 \\
\hline 7 & Installing cable trunk & 2 & 3 & 1 & 0 & 0 \\
\hline 8 & Install cable tray & 2 & 3 & 1 & 0 & 0 \\
\hline 9 & Water piping & 2 & 0 & 0 & 3 & 1 \\
\hline 10 & Return Piping & 2 & 0 & 0 & 3 & 1 \\
\hline 11 & Drainage piping & 2 & 0 & 0 & 3 & 1 \\
\hline 12 & Floor drains & 2 & 0 & 0 & 2 & 1 \\
\hline 13 & Cabling & 2 & 3 & 1 & 0 & 0 \\
\hline 14 & Installing power supply & 2 & 2 & 1 & 0 & 0 \\
\hline 15 & Structure of the air washer 1 & 3 & 0 & 1 & 0 & 1 \\
\hline 16 & Structure of the air washer 2 & 3 & 0 & 1 & 0 & 1 \\
\hline 17 & Install air washer 1 & 3 & 3 & 1 & 2 & 1 \\
\hline 18 & Install air washer 2 & 3 & 3 & 1 & 2 & 1 \\
\hline 19 & Connect cables and pipes of air & 1 & 2 & 1 & 2 & 1 \\
\hline 20 & Connect cables and pipes of air & 1 & 2 & 1 & 2 & 1 \\
\hline 21 & Re-installing lightning cables & 2 & 2 & 1 & 0 & 0 \\
\hline 22 & Re-installing lightning lamps & 2 & 2 & 1 & 0 & 0 \\
\hline 23 & Testing and site delivery & 2 & 2 & 1 & 2 & 1 \\
\hline
\end{tabular}

The precedence matrix is shown by Table 9 as follow. 
Table 9

Precedence matrix for the experiment

\begin{tabular}{cccccccccccccccccccccccccc}
\hline Activity ID & 1 & 2 & 3 & 4 & 5 & 6 & 7 & 8 & 9 & 10 & 11 & 12 & 13 & 14 & 15 & 16 & 17 & 18 & 19 & 20 & 21 & 22 & 23 \\
\hline 1 & 0 & 0 & 0 & 0 & 0 & 0 & 0 & 0 & 0 & 0 & 0 & 0 & 0 & 0 & 0 & 0 & 0 & 0 & 0 & 0 & 0 & 0 & 0 \\
2 & 1 & 0 & 0 & 0 & 0 & 0 & 0 & 0 & 0 & 0 & 0 & 0 & 0 & 0 & 0 & 0 & 0 & 0 & 0 & 0 & 0 & 0 & 0 \\
3 & 1 & 1 & 0 & 0 & 0 & 0 & 0 & 0 & 0 & 0 & 0 & 0 & 0 & 0 & 0 & 0 & 0 & 0 & 0 & 0 & 0 & 0 & 0 \\
4 & 0 & 0 & 1 & 0 & 0 & 0 & 0 & 0 & 0 & 0 & 0 & 0 & 0 & 0 & 0 & 0 & 0 & 0 & 0 & 0 & 0 & 0 & 0 \\
5 & 0 & 0 & 0 & 1 & 0 & 0 & 0 & 0 & 0 & 0 & 0 & 0 & 0 & 0 & 0 & 0 & 0 & 0 & 0 & 0 & 0 & 0 & 0 \\
6 & 1 & 0 & 0 & 0 & 0 & 0 & 0 & 0 & 0 & 0 & 0 & 0 & 0 & 0 & 0 & 0 & 0 & 0 & 0 & 0 & 0 & 0 & 0 \\
7 & 1 & 0 & 0 & 0 & 0 & 0 & 0 & 0 & 0 & 0 & 0 & 0 & 0 & 0 & 0 & 0 & 0 & 0 & 0 & 0 & 0 & 0 & 0 \\
8 & 0 & 0 & 0 & 0 & 0 & 0 & 1 & 0 & 0 & 0 & 0 & 0 & 0 & 0 & 0 & 0 & 0 & 0 & 0 & 0 & 0 & 0 & 0 \\
9 & 0 & 0 & 0 & 0 & 0 & 1 & 0 & 0 & 0 & 0 & 0 & 0 & 0 & 0 & 0 & 0 & 0 & 0 & 0 & 0 & 0 & 0 & 0 \\
10 & 0 & 0 & 0 & 0 & 0 & 1 & 0 & 0 & 0 & 0 & 0 & 0 & 0 & 0 & 0 & 0 & 0 & 0 & 0 & 0 & 0 & 0 & 0 \\
11 & 0 & 0 & 0 & 0 & 0 & 1 & 0 & 0 & 0 & 0 & 0 & 0 & 0 & 0 & 0 & 0 & 0 & 0 & 0 & 0 & 0 & 0 & 0 \\
12 & 0 & 0 & 0 & 0 & 0 & 0 & 0 & 0 & 1 & 1 & 1 & 0 & 0 & 0 & 0 & 0 & 0 & 0 & 0 & 0 & 0 & 0 & 0 \\
13 & 0 & 0 & 0 & 0 & 0 & 0 & 0 & 1 & 0 & 0 & 0 & 0 & 0 & 0 & 0 & 0 & 0 & 0 & 0 & 0 & 0 & 0 & 0 \\
14 & 0 & 0 & 0 & 0 & 0 & 0 & 0 & 0 & 0 & 0 & 0 & 0 & 1 & 0 & 0 & 0 & 0 & 0 & 0 & 0 & 0 & 0 & 0 \\
15 & 1 & 0 & 0 & 0 & 0 & 0 & 0 & 0 & 0 & 0 & 0 & 1 & 1 & 0 & 0 & 0 & 0 & 0 & 0 & 0 & 0 & 0 & 0 \\
16 & 0 & 0 & 0 & 0 & 0 & 0 & 0 & 0 & 0 & 0 & 0 & 1 & 1 & 0 & 0 & 0 & 0 & 0 & 0 & 0 & 0 & 0 & 0 \\
17 & 0 & 0 & 0 & 0 & 0 & 0 & 0 & 0 & 0 & 0 & 0 & 0 & 0 & 0 & 1 & 0 & 0 & 0 & 0 & 0 & 0 & 0 & 0 \\
18 & 0 & 0 & 0 & 0 & 0 & 0 & 0 & 0 & 0 & 0 & 0 & 0 & 0 & 0 & 0 & 1 & 0 & 0 & 0 & 0 & 0 & 0 & 0 \\
19 & 0 & 0 & 0 & 0 & 0 & 0 & 0 & 0 & 0 & 0 & 0 & 0 & 0 & 0 & 0 & 0 & 1 & 0 & 0 & 0 & 0 & 0 & 0 \\
20 & 0 & 0 & 0 & 0 & 0 & 0 & 0 & 0 & 0 & 0 & 0 & 0 & 0 & 0 & 0 & 0 & 0 & 1 & 0 & 0 & 0 & 0 & 0 \\
21 & 0 & 0 & 0 & 0 & 0 & 0 & 0 & 0 & 0 & 0 & 0 & 1 & 1 & 0 & 0 & 0 & 0 & 0 & 1 & 1 & 0 & 0 & 0 \\
22 & 0 & 0 & 0 & 0 & 0 & 0 & 0 & 0 & 0 & 0 & 0 & 0 & 0 & 0 & 0 & 0 & 0 & 0 & 0 & 0 & 1 & 0 & 0 \\
23 & 0 & 0 & 0 & 0 & 0 & 0 & 0 & 0 & 0 & 0 & 0 & 1 & 0 & 0 & 0 & 0 & 0 & 0 & 0 & 0 & 1 & 1 & 0 \\
\hline
\end{tabular}

All cash flow data are kept secret by the request of the company. For this purpose, the cash flows are changed in a logic manner. For example $12000 \$$ may show as $3.6 \$$ and so on. Fig. 12 shows the state of piping during the execution of the project. Fig. 13 shows the view of trimming saloon of IRANKHODRO Co. after finishing the project.

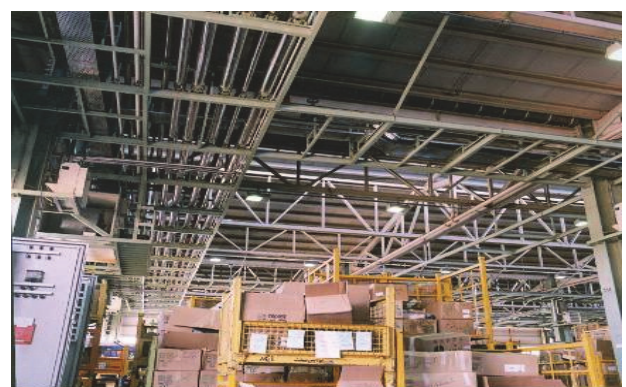

Fig. 12. Image of the Piping activitie

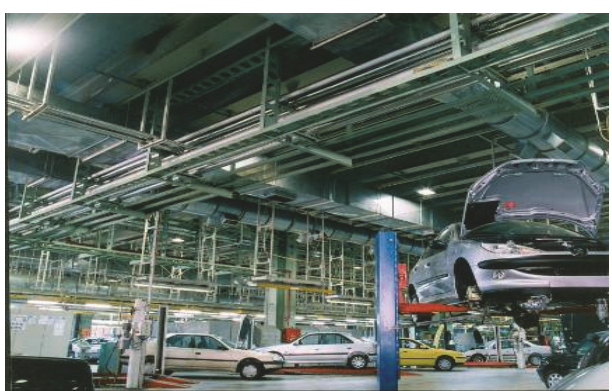

Fig. 13. The image of the project after completion

After solving the project with the proposed method, the upper feasibility control limit is observed as 261 working days. Then similar to the experiments in previous section, this experiment is solved first by considering enough resource throughout the project. As shown by Fig. 14, the completion time is observed 100 working days in this condition.

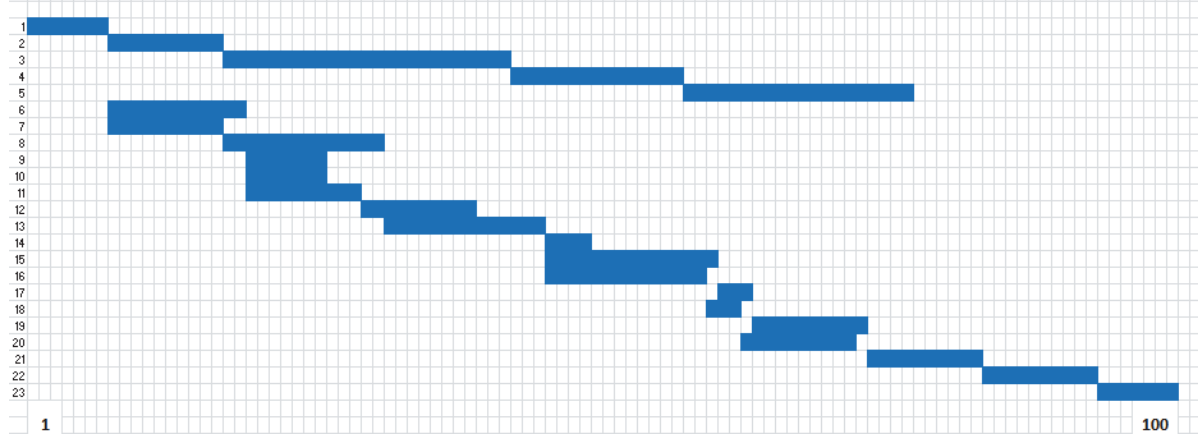

Fig. 14. Gantt chart of the validating experiment with relaxed resource constraints 
Then, the algorithm has been solved again by using the real available data gathered from the technical department of the company and Table 10 summarizes the results.

Table 10

Available resources for the validating experiment

\begin{tabular}{lccccc}
\hline Resource & $\begin{array}{c}\text { Simple } \\
\text { worker }\end{array}$ & $\begin{array}{c}\text { Electrical } \\
\text { worker }\end{array}$ & $\begin{array}{c}\text { Electrical } \\
\text { Technician }\end{array}$ & $\begin{array}{c}\text { Mechanical } \\
\text { worker }\end{array}$ & $\begin{array}{c}\text { Mechanical } \\
\text { Technician }\end{array}$ \\
\hline Capacity & 20 & 25 & 20 & 25 & 20 \\
\hline
\end{tabular}

The algorithm could achieve the steady state by postponing the activities in their free float period. Thus, no split activity is reported in Fig. 15. The makespan under this condition is extended to 124 working days. The symbolic profit of the project is reported $12427 \$ 1$.

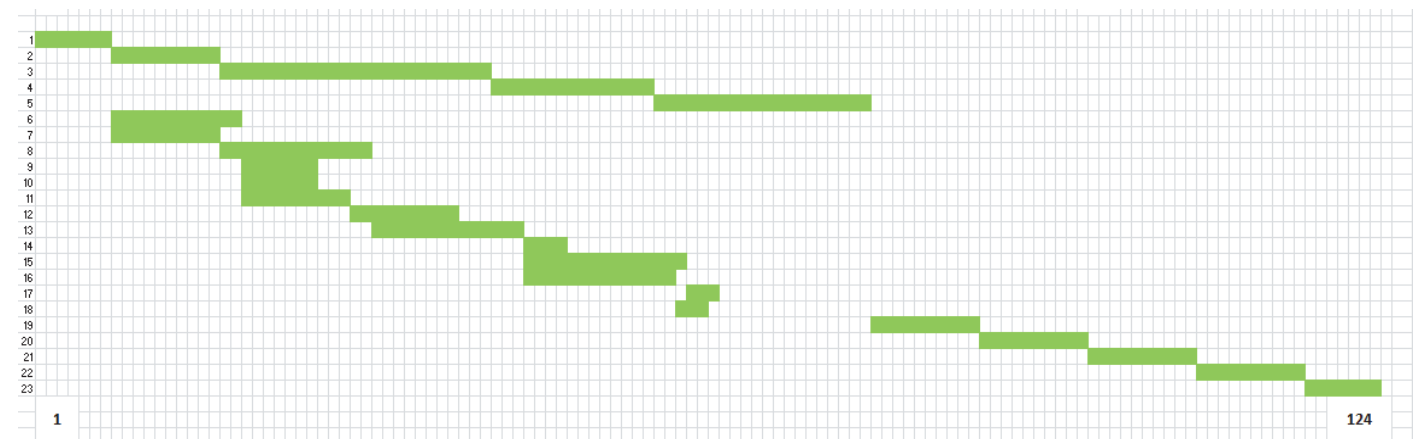

Fig. 15. Gantt chart of the validating experiment after using the proposed forward method

\section{Conclusion and recommendations}

Scheduling multi-mode resource constraint project scheduling problems with the existence of preemptive resources has been a big concern in project management. In this research a new method was developed for modifying the over-allocated project schedules while preemptive resources were taken into account. For this purpose a new forward programming heuristic has been proposed. The proposed method was based on positive cash flow priority and activity id rules. It has been observed that the proposed method can modify over-allocated MRCPSPs schedules by taking apart less important activities and keeping more important activities. It is also observed that while modifying the over-allocated schedules, the makespan is increased in all studied cases. Further expansion of the research by considering negative cash flows and non-renewable resources have been suggested.

\section{Acknowledgment}

The authors would like to thank the editor and anonymous reviewers for their positive comments through the progressing period.

\section{References}

Abbasi, B., Shadrokh, S., \& Arkat, J. (2006). Bi-objective resource-constrained project scheduling with robustness and makespan criteria. Applied Mathematics and Computation, 180(1), 146-152.

Achuthan, N., \& Hardjawidjaja, A. (2001). Project scheduling under time dependent costs-A branch and bound algorithm. Annals of Operations Research, 108(1-4), 55-74.

Alcaraz, J., \& Maroto, C. (2001). A robust genetic algorithm for resource allocation in project scheduling. Annals of Operations Research, 102(1-4), 83-109.

${ }^{1}$. As mentioned before, all cash flow data are kept secret by the request of the company. For this purpose, the cash flows are changed in a logic manner. 
Ballestín, F., Valls, V., \& Quintanilla, S. (2008). Pre-emption in resource-constrained project scheduling. European Journal of Operational Research, 189(3), 1136-1152.

Baroum, S. M., \& Patterson, J. H. (1999). An exact solution procedure for maximizing the net present value of cash flows in a network Project Scheduling (pp. 107-134): Springer.

Buddhakulsomsiri, J., \& Kim, D. S. (2006). Properties of multi-mode resource-constrained project scheduling problems with resource vacations and activity splitting. European Journal of Operational Research, 175(1), 279-295.

Castejón-Limas, M., Ordieres-Meré, J., González-Marcos, A., \& González-Castro, V. (2011). Effort estimates through project complexity. Annals of Operations Research, 186(1), 395-406.

Chtourou, H., \& Haouari, M. (2008). A two-stage-priority-rule-based algorithm for robust resourceconstrained project scheduling. Computers \& industrial engineering, 55(1), 183-194.

Damay, J., Quilliot, A., \& Sanlaville, E. (2007). Linear programming based algorithms for preemptive and non-preemptive RCPSP. European Journal of Operational Research, 182(3), 1012-1022.

De Reyck, B. (1998). A branch-and-bound procedure for the resource-constrained project scheduling problem with generalized precedence relations. European Journal of Operational Research, 111(1), 152-174.

Delgoshaei, A., Ariffin, M. K., Baharudin, B. H. T. B., \& Leman, Z. (2014). A Backward Approach for Maximizing Net Present Value of Multi-mode Pre-emptive Resource-Constrained Project Scheduling Problem with Discounted Cash Flows Using Simulated Annealing Algorithm. International Journal of Industrial Engineering and Management, 5(3), 151-158.

Delgoshaei, A., Ariffin, M. K. M., Baharudin, B. H. T. B., \& Leman, Z. (2015). Minimizing makespan of a resource-constrained scheduling problem: A hybrid greedy and genetic algorithms. Resource.

Demeulemeester, E. L., \& Herroelen, W. S. (1996). An efficient optimal solution procedure for the preemptive resource-constrained project scheduling problem. European Journal of Operational Research, 90(2), 334-348.

Elmaghraby, S. E., \& Herroelen, W. S. (1990). The scheduling of activities to maximize the net present value of projects. European Journal of Operational Research, 49(1), 35-49.

Etgar, R., Shtub, A., \& LeBlanc, L. J. (1997). Scheduling projects to maximize net present value - the case of time-dependent, contingent cash flows. European Journal of Operational Research, 96(1), 90-96.

Hartmann, S. (2001). Project scheduling with multiple modes: a genetic algorithm. Annals of Operations Research, 102(1-4), 111-135.

Hartmann, S., \& Briskorn, D. (2010). A survey of variants and extensions of the resource-constrained project scheduling problem. European Journal of Operational Research, 207(1), 1-14.

Icmeli, O., \& Erenguc, S. S. (1994). A tabu search procedure for the resource constrained project scheduling problem with discounted cash flows. Computers \& operations research, 21(8), 841853.

Icmeli, O., Erenguc, S. S., \& Zappe, C. J. (1993). Project scheduling problems: a survey. International Journal of Operations \& Production Management, 13(11), 80-91.

Jarboui, B., Damak, N., Siarry, P., \& Rebai, A. (2008). A combinatorial particle swarm optimization for solving multi-mode resource-constrained project scheduling problems. Applied Mathematics and Computation, 195(1), 299-308.

Ke, H., \& Liu, B. (2010). Fuzzy project scheduling problem and its hybrid intelligent algorithm. Applied Mathematical Modelling, 34(2), 301-308.

Kelley, J. E. (1963). The critical-path method: Resources planning and scheduling. Industrial scheduling, 13, 347-365.

Kim, K., Yun, Y., Yoon, J., Gen, M., \& Yamazaki, G. (2005). Hybrid genetic algorithm with adaptive abilities for resource-constrained multiple project scheduling. Computers in industry, 56(2), 143160.

Kolisch, R. (1996). Serial and parallel resource-constrained project scheduling methods revisited: Theory and computation. European Journal of Operational Research, 90(2), 320-333. 
Kolisch, R., \& Drexl, A. (1997). Local search for nonpreemptive multi-mode resource-constrained project scheduling. IIE transactions, 29(11), 987-999.

Laslo, Z. (2010). Project portfolio management: An integrated method for resource planning and scheduling to minimize planning/scheduling-dependent expenses. International Journal of Project Management, 28(6), 609-618.

Lee, C.-Y., \& Lei, L. (2001). Multiple-project scheduling with controllable project duration and hard resource constraint: some solvable cases. Annals of Operations Research, 102(1-4), 287-307.

Lova, A., \& Tormos, P. (2001). Analysis of scheduling schemes and heuristic rules performance in resource-constrained multiproject scheduling. Annals of Operations Research, 102(1-4), 263-286.

Mika, M., Waligóra, G., \& Węglarz, J. (2005). Simulated annealing and tabu search for multi-mode resource-constrained project scheduling with positive discounted cash flows and different payment models. European Journal of Operational Research, 164(3), 639-668.

Peteghem, V. V., \& Vanhoucke, M. (2010). A genetic algorithm for the preemptive and non-preemptive multi-mode resource-constrained project scheduling problem. European Journal of Operational Research, 201(2), 409-418.

Russell, A. (1970). Cash flows in networks. Management Science, 16(5), 357-373.

Seifi, M., \& Tavakkoli-Moghaddam, R. (2008). A new bi-objective model for a multi-mode resourceconstrained project scheduling problem with discounted cash flows and four payment models. Int. J. of Engineering, Transaction A: Basic, 21(4), 347-360.

Sprecher, A. (2000). Scheduling resource-constrained projects competitively at modest memory requirements. Management Science, 46(5), 710-723.

Sung, C., \& Lim, S. (1994). A project activity scheduling problem with net present value measure. International Journal of Production Economics, 37(2), 177-187.

Talbot, F. B. (1982). Resource-constrained project scheduling with time-resource tradeoffs: The nonpreemptive case. Management Science, 28(10), 1197-1210.

Van de Vonder, S., Demeulemeester, E., Herroelen, W., \& Leus, R. (2005). The use of buffers in project management: The trade-off between stability and makespan. International Journal of Production Economics, 97(2), 227-240.

Van de Vonder, S., Demeulemeester, E., Herroelen, W., \& Leus, R. (2006). The trade-off between stability and makespan in resource-constrained project scheduling. International Journal of Production Research, 44(2), 215-236.

Węglarz, J., Józefowska, J., Mika, M., \& Waligóra, G. (2011). Project scheduling with finite or infinite number of activity processing modes-A survey. European Journal of Operational Research, 208(3), 177-205.

Yan, L., Jinsong, B., Xiaofeng, H., \& Ye, J. (2009). A heuristic project scheduling approach for quick response to maritime disaster rescue. International Journal of Project Management, 27(6), 620628.

Yang, K. K., Talbot, F. B., \& Patterson, J. H. (1993). Scheduling a project to maximize its net present value: an integer programming approach. European Journal of Operational Research, 64(2), 188198.

Yu, L., Wang, S., Wen, F., \& Lai, K. K. (2012). Genetic algorithm-based multi-criteria project portfolio selection. Annals of Operations Research, 197(1), 71-86.

Zhou, M., \& Askin, R. G. (1998). Formation of general GT cells: an operation-based approach. Computers \& industrial engineering, 34(1), 147-157.

Zhu, D., \& Padman, R. (1999). A metaheuristic scheduling procedure for resource-constrained projects with cash flows. Naval Research Logistics (NRL), 46(8), 912-927. 